\title{
Structural and Mechanical Evaluation of A Nanocrystalline Al-5 wt \%Si Alloy Produced by Mechanical Alloying
}

\author{
Davood Dayani ${ }^{1}$, Ali Shokuhfar ${ }^{1}$, Mohammad Reza Vaezi ${ }^{2}$, Seyed Reza Jafarpour Rezaei ${ }^{3}$ \\ and Saman Hosseinpour $4, *$ \\ 1 Department of Engineering, Karaj Branch, Islamic Azad University, 3148635731 Karaj, Iran; \\ dayanidavood@gmail.com (D.D.); shokuhfar@kntu.ac.ir (A.S.) \\ 2 Division of Nanotechnology and Advanced Materials, Materials and Energy Research Center, \\ 3177983634 Karaj, Iran; m_r_vaezi@merc.ac.ir \\ 3 Department of Materials Science and Engineering, School of Engineering, Shiraz University, Zand Avenue, \\ 7134814666 Shiraz, Iran; rezajafarpour2010@gmail.com \\ 4 Institute of Particle Technology (LFG), University of Erlangen-Nuremberg, Cauerstrasse 4, \\ 91058 Erlangen, Germany \\ * Correspondence: saman.hosseinpour@fau.de; Tel.: +49-9131-8529580
}

Received: 7 July 2017; Accepted: 20 August 2017; Published: 29 August 2017

\begin{abstract}
High energy mechanical milling followed by hot-pressing consolidation has been used to produce nanostructured Al-5 wt \%Si alloy. X-ray diffraction (XRD), scanning electron microscopy equipped with energy dispersive X-ray detector (SEM-EDX), Vickers hardness, and compression measurements were used to examine the effect of milling duration on microstructure and mechanical properties of the nanostructured consolidated alloys. Crystallite sizes and lattice strains were determined by X-ray peak broadening analysis using the Williamson-Hall (W-H) method. Increasing the milling time reduced the crystallite size, and the minimum crystallite size of about $33 \mathrm{~nm}$ was achieved for both consolidated and powdered samples after $50 \mathrm{~h}$ of milling. Based on the SEM-EDX observations, the best distribution of silicon into Al matrix was obtained after $20 \mathrm{~h}$ of milling and remained unchanged afterwards. Hardness of both consolidated and powder samples increased with milling time, which can be attributed to the reduction of crystallite size and the better distribution of silicon in the aluminum matrix. Similarly, increased milling time increased the yield and compressive strengths of consolidated samples.
\end{abstract}

Keywords: mechanical alloying; Al-Si alloy; mechanical properties; consolidation

\section{Introduction}

Since mechanical alloying (MA) was first used in 1970 by Benjamin to produce iron and nickel base superalloys [1], Ma has attracted a significant amount of attention for synthesizing novel materials with unique properties [2]. Ma is able to produce both equilibrium and non-equilibrium phases and materials with improved properties compared to their conventionally produced counterparts $[3,4]$. Ma leads to a remarkable improvement in the mechanical properties of alloys through the homogeneous dispersion of particles along with the reduction of grain size to a nanometer scale [5,6]. Furthermore, Ma improves microstructural stability such as creep resistance at elevated temperatures, which is associated with a suitable dispersion of nanoparticles in the microstructure that prevent high temperature coarsening [7]. The advantages of Ma compared to other conventional alloying methods, such as processing in low temperatures, an improved microstructural refinement, uniform chemical composition, and a lack of solidification defects, have turned Ma into a convenient technique for producing aluminum alloys, composites, and coatings involving aluminum and silicon [8-11]. Mechanically produced Al-Si alloys 
have been widely used in various fields, such as automotive and aerospace industries, due to their high strength-to-weight ratio, excellent wear resistance, and low thermal expansion coefficient [12]. For practical applications, consolidation, which involves sequences of sintering processes, is a necessary step in the production of desired Al-Si alloys. Hot consolidation that requires the simultaneous application of temperature and pressure is the method of choice for various applications since it increases the chance of the fast and full densification of powders. Furthermore, the formation of unwanted phases or microstructural changes can be prevented by hot consolidation [13].

In the present study, we investigate the nanocrystalline structure of Al-5 wt \%Si powders produced by Ma as well as the consolidated alloy after the powders are hot-pressed. The mechanical properties of the produced alloys are assessed using compression and hardness tests, and the microstructural changes and their effects on the mechanical properties of alloys are investigated.

\section{Materials and Methods}

A mixture of commercial aluminum powders (with $99.9 \%$ purity and a particle size of $<75 \mu \mathrm{m}$, Sigma-Aldrich, St. Louis, MO, USA) and silicon powders (with $99.9 \%$ purity and a particle size of $<20 \mu \mathrm{m}$, Alfa Aesar, Haverhill, MA, USA) was milled in a planetary ball mill under an argon atmosphere to achieve an alloy with a composition of $\mathrm{Al}-5 \mathrm{wt} \% \mathrm{Si}$. The following parameters were used in the milling process: a ball-to-powder mass ratio of 12:1, a ball diameter of $10 \mathrm{~mm}$, and a speed of $250 \mathrm{rpm}$. We added $1.5 \mathrm{wt} \%$ of stearic acid $\left(\mathrm{CH}_{3}\left(\mathrm{CH}_{2}\right)_{16} \mathrm{COOH}\right)$ to the mixture as a process control agent (PCA) to moderate the cold welding process and to prevent the adhesion of the powder to the balls and interior surface of the milling tank. The mixture of powders and PCA was milled for up to $50 \mathrm{~h}$, and samples were collected after 5, 20, and $50 \mathrm{~h}$ of milling. Mechanically alloyed powders were uniaxially cold-pressed in a cylindrical steel die (a diameter of $10 \mathrm{~mm}$ ) for $30 \mathrm{~s}$ at $500 \mathrm{MPa}$ pressure and then hot-pressed for $60 \mathrm{~min}$ at $450{ }^{\circ} \mathrm{C}$ under $500 \mathrm{MPa}$ to achieve the consolidated samples. Crystallite size, lattice strain, and hardness of the consolidated samples were compared to their powder counterparts.

$X$-ray diffraction measurements were performed with a wide angle diffractometer in the $\theta-2 \theta$ step scan mode using $\mathrm{CuK} \alpha$ radiation. Scans were collected over a $2 \theta$ range of $20-90^{\circ}$ with a step of $0.01^{\circ}$. The crystallite size $(d)$ and the equivalent lattice strain $(\varepsilon)$ were determined using the Williamson-Hall $(\mathrm{W}-\mathrm{H})$ line broadening analysis method [14] according to the following:

$$
\beta \cos \theta=\frac{\mathrm{k} \lambda}{d}+2 \varepsilon \sin \theta
$$

where $\beta$ is the full width at half maximum (FWHM) of the diffraction peak, $\theta$ is the diffraction angle, $\mathrm{k}$ is a constant whose values is approximately 0.9 , and $\lambda$ is the incident $X$-ray wavelength $(1.54060 \AA)$.

It is clear from Equation (1) that $\beta \cos \theta$ vs. $\sin \theta$ curve exhibits a straight line with the slope of $(2 \varepsilon)$ and intercept of $\mathrm{k} \lambda / d$. Thus, the crystallite size $(d)$ and the lattice strain $(\varepsilon)$ can be achieved.

Scanning electron microscope (SEM) equipped with an energy dispersive $X$-ray spectrometer (EDX, VEGA/TESCAN, Kohoutovice, Czech Republic) was used in characterizing the microstructure of the samples as well as analyzing the elemental distribution. Additionally, to evaluate the hardness of MA-prepared powders, a micro-hardness test was utilized using a Vickers indenter under the load of $10 \mathrm{gf}$ and dwell time of $15 \mathrm{~s}$ (MVK-H21, Akashi Co., Hyogo, Japan). For harness measurements of consolidated samples, a load of $25 \mathrm{gf}$ and a dwell time of $15 \mathrm{~s}$ was used. Measuring the hardness of powders is a challenging issue and usually results in scattered values dependent on the method of the measurement, on the properties of the mounting resin, and on the "depth" of the particle under indenter [15]. In this study, we used hot epoxy resin to mount the cold-pressed powders prior the micro-hardness measurements. The excess of the resin was removed from the top layer, exposing the surface of powders to air. The micro-hardness of the powders was estimated by the evaluation of the depth of the indentation. The choice of low load for the hardness measurements on powdered samples was to reduce the indenter impression and its depth, allowing reasonable hardness measurements on small powders. a similar method was employed earlier by Abdoli et al. to evaluate the micro-hardness 
of nanostructured composite powders produced by MA [16]. For better statistics of the hardness values, the hardness tests were performed on three individual points on each consolidated sample and on 10 points for each powdered sample. Moreover, compression testing on consolidated sample was carried out at a cross-head speed of $0.2 \mathrm{~mm} / \mathrm{min}$ and a strain rate of $0.005 \mathrm{~min}^{-1}$. Prior to the compression tests, both ends of the specimens were polished to make them parallel to each other.

\section{Results}

Figure 1 shows the changes in the morphology of mixed powders with increasing milling times. As Figure 1 shows, increasing milling time gradually changes the powder morphology from flat flakes to semi-globular structures. As is expected, in preliminary stages of milling (Figure 1a) aluminum particles are still soft, and they undergo plastic deformation while brittle silicon particles are fragmented. The Si phase is believed to accelerate the deformation of the powder through a second hard phase formation in the mill [17]. Increasing the milling time results in the sequential welding of the aluminum particles and the distribution of silicon particles within the aluminum matrix. With the continuation of milling (Figure 1b), various factors such as deformation, welding, and solid dispersion lead to work hardening of aluminum particles, which in turn enhances their tendency to fracture. Thus, aluminum particles break down, and the average particle size slightly decreases. Finally, welding and fracture processes reach an equilibrium (Figure 1c) where randomly orientated boundaries are formed. In this stage, particles becomes semi-globular in shape, and their size distribution becomes more uniform.
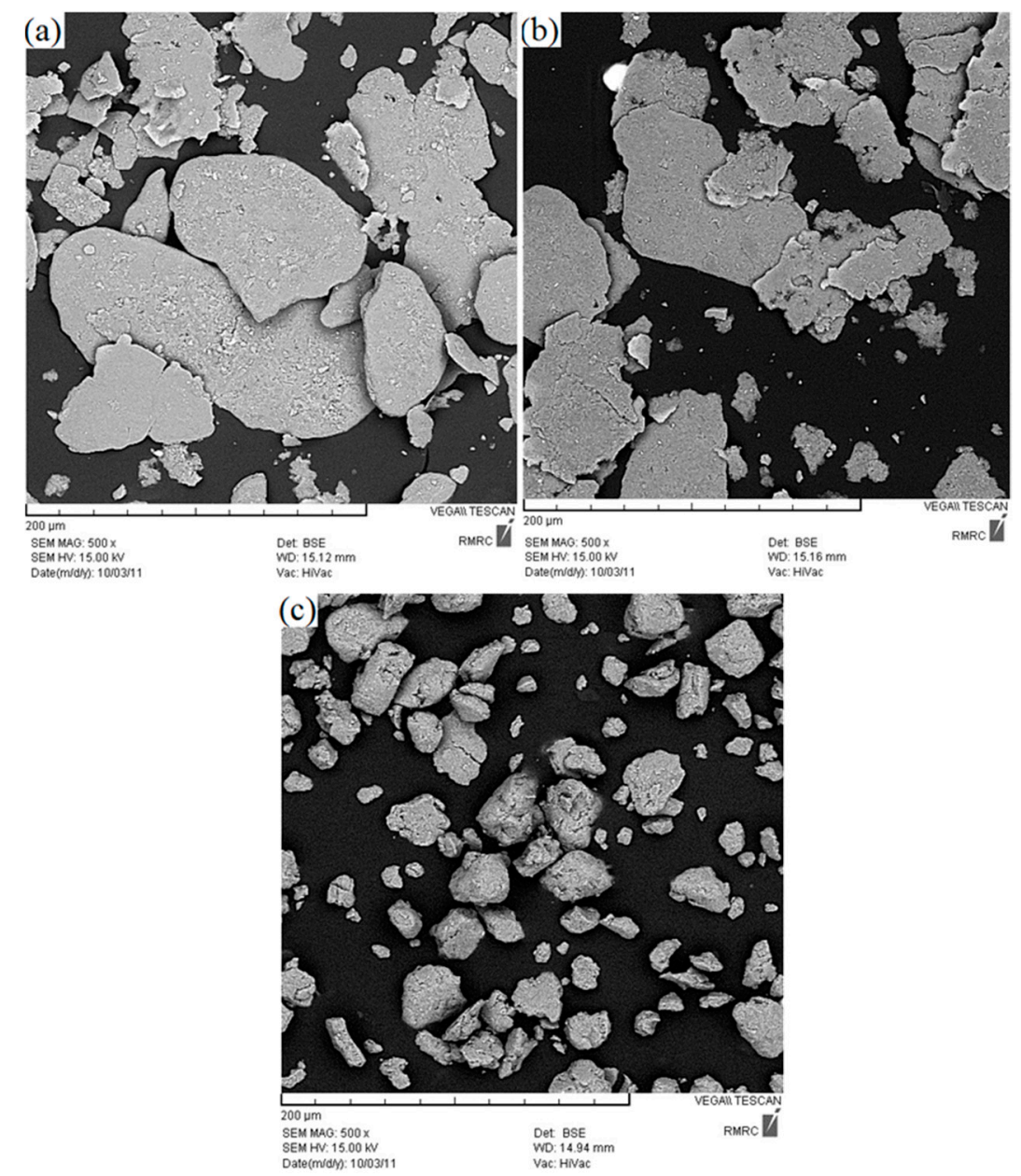

Figure 1. Scanning electron microscope (SEM) images of Al-5 wt \%Si powders for different milling durations: (a) $5 \mathrm{~h},(\mathbf{b}) 20 \mathrm{~h}$, and (c) $50 \mathrm{~h}$. 
Figure 2 shows an individual semi-globular particle formed after $50 \mathrm{~h}$ of milling. As can be seen from this figure, the surface of the semi-globular particle exhibits some moderate roughness as a consequence of simultaneous competition of welding and fracturing mechanisms. Although Figure 2 exhibits a typical particle shape after $50 \mathrm{~h}$ of milling, as can be observed in Figure 1c, there are instances of a transverse crack through the whole particle is observed, most likely due to the increase in the internal stresses and lattice strains within the semi-globular particles, which will be discussed in the following.

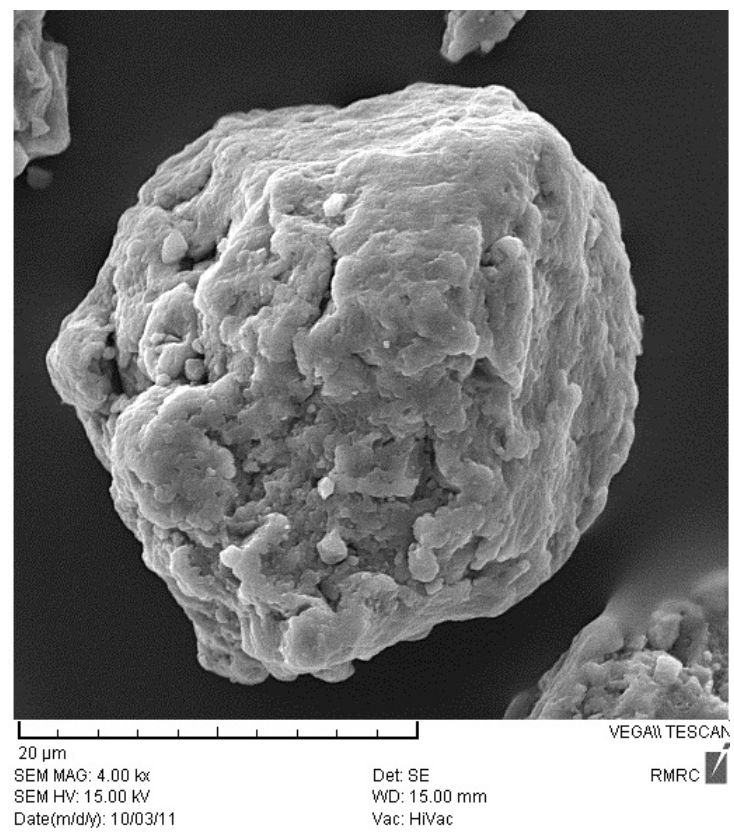

Figure 2. SEM image of semi-globular particle of Al-5 wt \%Si formed after $50 \mathrm{~h}$ of milling.

From XRD analysis, the crystallite size and lattice strain were measured, and the obtained values are summarized in Tables 1 and 2 for the powder and consolidated samples, respectively. In all cases a decreasing trend in the crystallite size is observed upon increasing the milling time. As proposed by Miraghaei et al. [18], the formation of new defects, especially dislocations, is responsible for the reduction of the crystallite size. Multiple mechanisms were proposed for the accumulation of dislocations. For instance, dense regions of these dislocations can be formed in sub grains, dislocations might pile up at the grain boundaries, or clusters can be accommodated within the crystallites. Overall, a severe plastic deformation during mechanical alloying and consequently the reduction of the crystallite size can contribute to the generation of extra dislocations. Moreover, the results in Tables 1 and 2 indicate that the lattice strain is generally enhanced as the milling time increases. As mentioned before, the severe plastic deformation during the milling process introduces dislocations, vacancies, impurities, and other lattice defects, which, in turn, increase the stress field in the alloys. Similar trends were observed for mechanically produced $\mathrm{Al}-\mathrm{Mg} / \mathrm{Al}_{2} \mathrm{O}_{3}$ nanocomposites, $\mathrm{Al} / \mathrm{Fe}$ alloys, and alumina-reinforced nanocrystals [19-21].

Table 1. Crystallite size (nm) and lattice strain of powder as functions of milling time (h), determined by the Williamson-Hall (W-H) method.

\begin{tabular}{ccc}
\hline Time $(\mathbf{h})$ & $\boldsymbol{d}(\mathbf{W}-\mathbf{H})$ & $\boldsymbol{\varepsilon}(\mathbf{W}-\mathbf{H})$ \\
\hline 5 & 47.8 & $2.2 \times 10^{-3}$ \\
20 & 33.8 & $2.8 \times 10^{-3}$ \\
30 & 32.6 & $2.8 \times 10^{-3}$ \\
50 & 32.6 & $4.3 \times 10^{-3}$ \\
\hline
\end{tabular}


Table 2. Crystallite size (nm) and lattice strain of bulk samples as functions of milling time (h), determined by the W-H method.

\begin{tabular}{ccc}
\hline Time (h) & $\boldsymbol{d}(\mathbf{W}-\mathrm{H})$ & $\boldsymbol{\varepsilon}(\mathrm{W}-\mathrm{H})$ \\
\hline 5 & 50.2 & $1.5 \times 10^{-3}$ \\
20 & 35.43 & $2.0 \times 10^{-3}$ \\
30 & 33.4 & $2.1 \times 10^{-3}$ \\
50 & 33.0 & $2.7 \times 10^{-3}$ \\
\hline
\end{tabular}

In the current study, the initial growth of the average particle diameter due to a flattening of the particles, similar to the observations by Milligan et al. [17], is neglected as it is out of the scope of this work. However, a partial crystallite growth is observed for the consolidated samples during the hot pressing stage. Nevertheless, the extensive crystal growth is still retarded due to the pinning effects at the grain boundaries [22]. Explaining such trends for consolidated samples requires a better understanding of the elemental composition distribution, which will be discussed later. As is depicted in Figure 3, the variation of the crystallite size with the increase in milling time exhibits very similar trends for powder and consolidated samples, showing that, after almost $20 \mathrm{~h}$ of milling, the size of crystals do not vary any more for either sample.

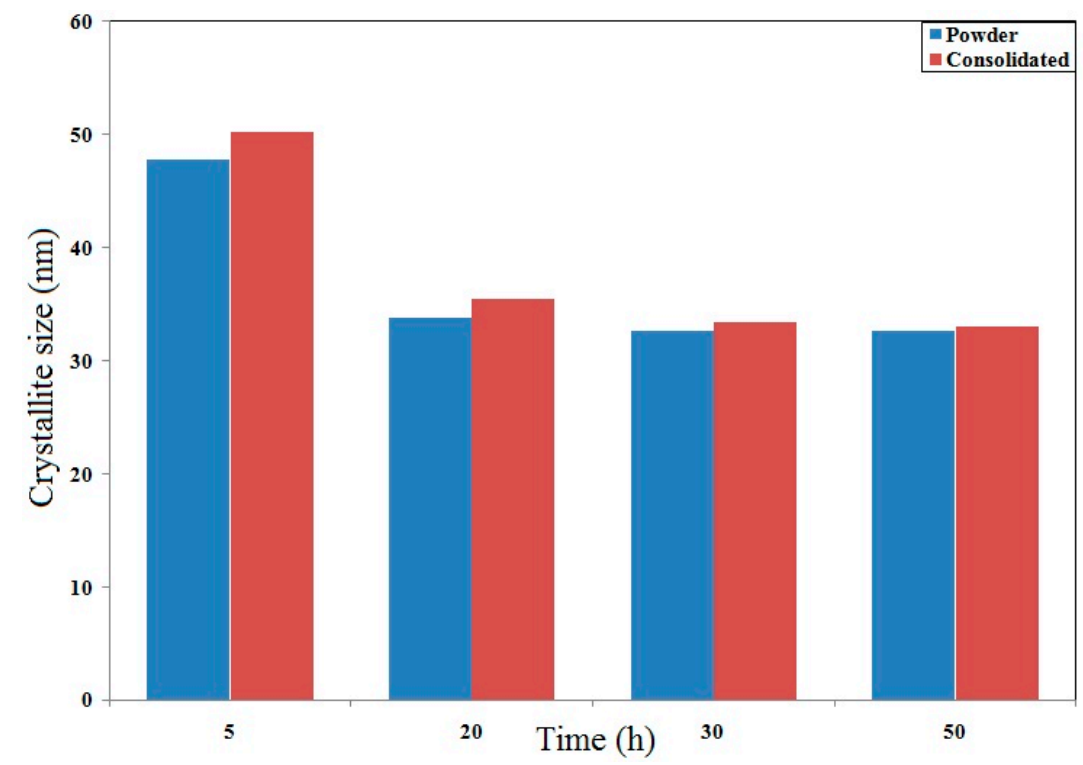

Figure 3. Crystallite size (nm) as a function of milling time (h) for powder and consolidated samples determined by the $\mathrm{W}-\mathrm{H}$ method.

To understand how the distribution of $\mathrm{Si}$ in the aluminum matrix affects the crystallite size and the growth rate by the pinning mechanism, EDX measurements are performed on selected consolidated samples. As can be seen in Figure 4, Si distribution in the Al matrix is more uniform after a prolonged milling time (i.e., $20 \mathrm{~h}$ ), causing a better pinning of the grain boundaries, which in turn prevents the crystalline growth. 

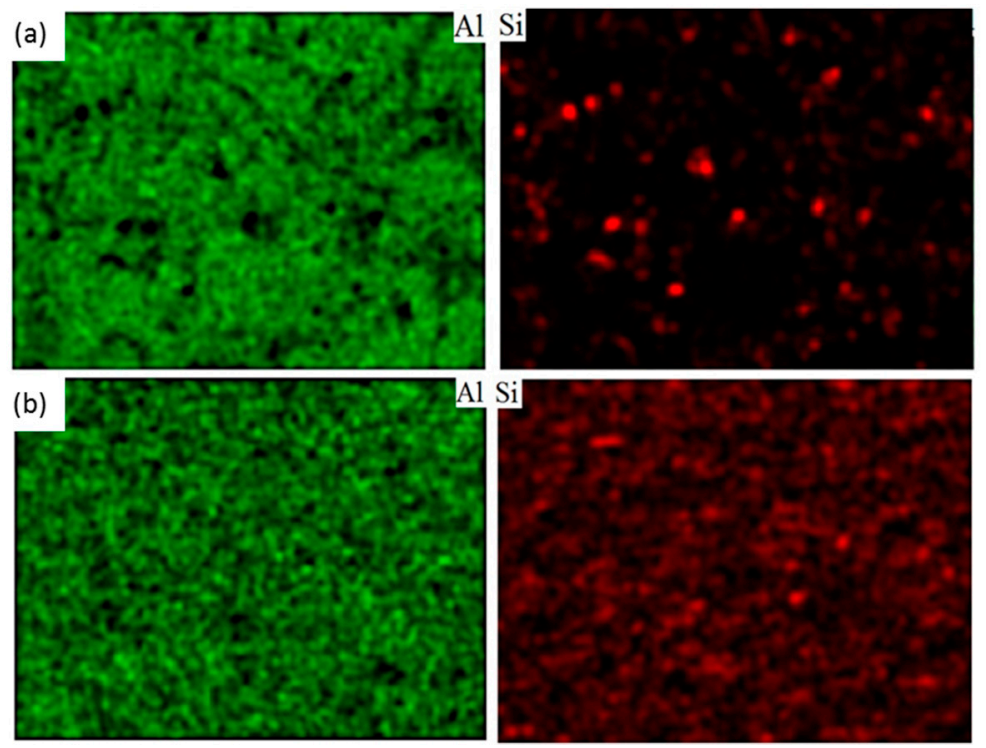

Figure 4. Energy dispersive X-ray spectroscopy (EDX) analysis of consolidated samples with milling time (a) $5 \mathrm{~h}$ and (b) $20 \mathrm{~h}$ of milling.

The distribution of $\mathrm{Si}$ in the $\mathrm{Al}$ matrix as well as the residual internal stress within the crystals affect the hardness of the powders and consolidated samples. Variation in the hardness of the Al-5 wt \%Si powders and consolidated samples as a function of milling time is shown in Figure 5. Both crystallite size reduction and elemental dispersion strengthening affect the hardness of samples. Based on these results, the measured hardness for both powdered and consolidated samples is almost monotonically enhanced when the milling time is increased, reaching its maximum value at around $50 \mathrm{~h}$ of milling time. However, the consolidated samples show greater absolute hardness values compared to their powder counterparts most likely due to the distribution of the internal stress within their structure (see Tables 1 and 2). It is worth noting that microhardness measurements performed on powder particles are inherently prone to systematic errors. Therefore, microhardness value comparisons between the powder specimens and the consolidated specimens should be considered approximations at best. Despite almost a constant grain size after $20 \mathrm{~h}$ of milling (results from Figure 3), overall hardness values increase when the milling time is increased. These phenomena point to the fact that, in addition to grain reinforcement, certain mechanisms, such as work hardening of the fragile fragments in the initial stages of milling, the homogeneous distribution of Si atoms in the Al matrix, and its possible oversaturation, lattice microstrains, as well as the formation and distribution of defects within newly formed crystals, affect the final mechanical properties of the alloys. However, quantification of the fractal contributions of these mechanisms is out of the scope of the current manuscript.

Figure 6 presents yield and compressive strengths of consolidated samples for various milling time. Similar to hardness test results (results from Figure 5), strength values increase with milling time reaching a maximum yield strength after $50 \mathrm{~h}$ of milling. It is known that the grain boundaries result in a higher yield stress than the matrix itself, since grain boundaries are able to prevent dislocation movement [21]. In other words, dislocations pile up behind grain boundaries resulting in a stress concentration. Since increasing the milling time reduces the grain size, it will also strengthen the material, resulting in an increase in its yield stress. Furthermore, a better distribution of silicon in the aluminum matrix as well as work hardening can contribute to the increased yield strength of consolidated samples as the milling time increases [23,24]. 


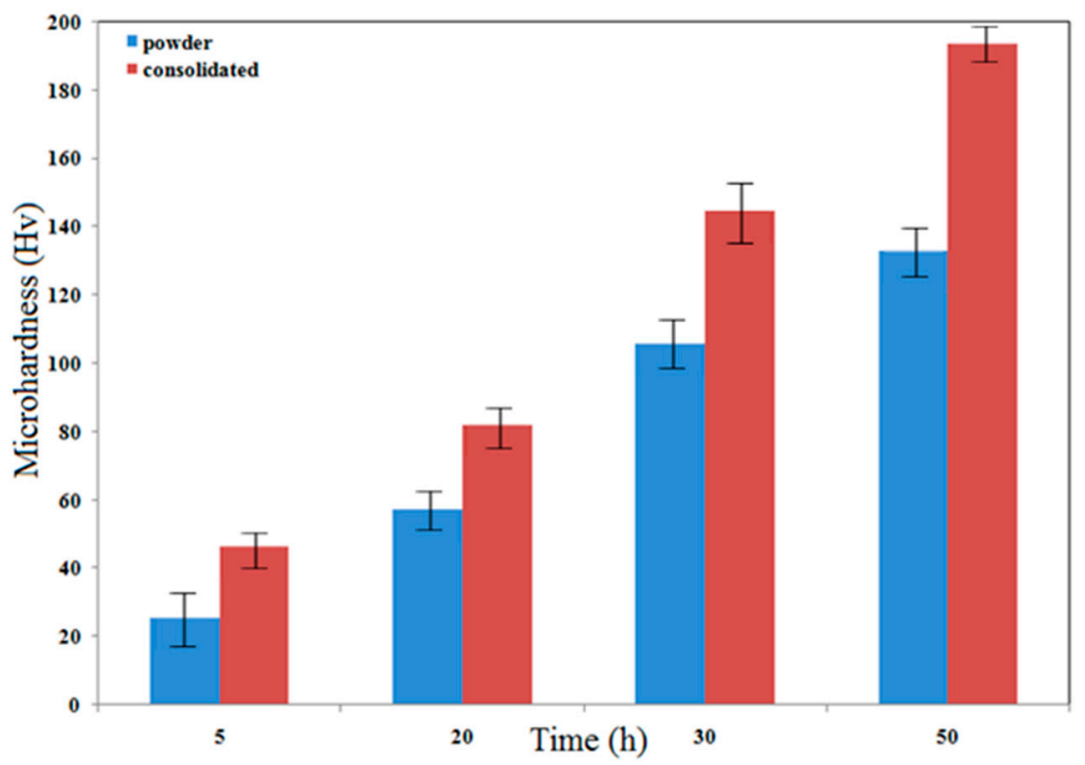

Figure 5. Microhardness values (Hv) of Al-5 wt \%Si powder and consolidated samples as a function of the milling time $(\mathrm{h})$.

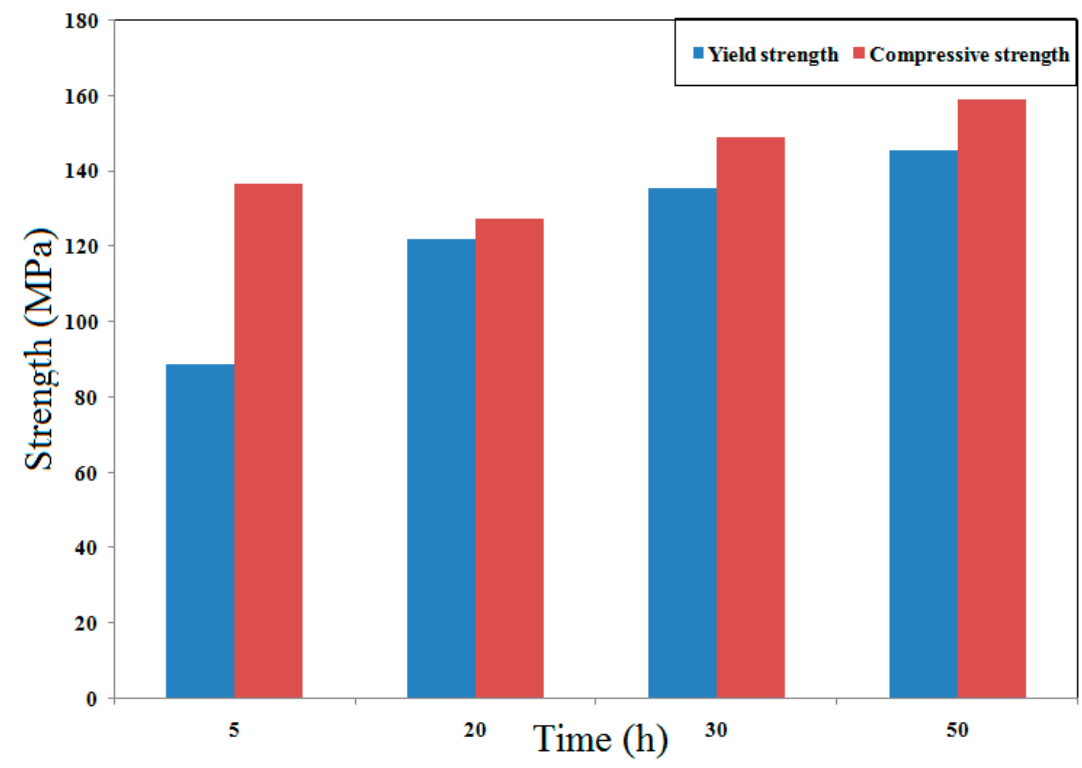

Figure 6. Yield and compressive strengths (MPa) of consolidated samples as a function of the milling time (h).

\section{Conclusions}

In the present study, nanocrystalline Al-5 wt \%Si powder was successfully synthesized by mechanical alloying under an argon atmosphere followed by consolidation using a hot pressing process. Morphology changes of powders revealed that milling, welding of the soft aluminum particles, and the consequent fracture of brittle structures are major competing mechanisms in the first $50 \mathrm{~h}$ of milling, leading to an equilibrium semi-globular structure for particulate samples. Evaluation of the crystallite size through analysis of the XRD patterns for both consolidated and powder samples indicated a nanometric crystallite size, which decreases when the milling duration is increased. Consolidation in the hot pressing process led to only a minute crystallite size growth. SEM-EDX studies of the consolidated samples showed that the distribution of $\mathrm{Si}$ in the $\mathrm{Al}$ matrix is uniform throughout the 
sample after $20 \mathrm{~h}$ of milling, which brings about minimal crystallite size growth. It was also observed that mechanical properties of the consolidated samples such as hardness values and compression strength enhance as the milling time increases as a consequence of uniform distribution of elements and work hardening.

Acknowledgments: The corresponding author would like to acknowledge the FAU library for their support for covering the $25 \%$ of the costs to publish in open access.

Author Contributions: Davood Dayani and Seyed Reza Jafarpour Rezaei conceived, designed, and performed the experiments; Davood Dayani wrote a part of the paper; Mohammad Reza Vaezi, Ali Shokuhfar, and Saman Hosseinpour supervised the work; Saman Hosseinpour wrote the paper.

Conflicts of Interest: The authors declare no conflict of interest.

\section{References}

1. Benjamin, J.S. Dispersion strengthened superalloys by mechanical alloying. Metall. Trans. 1970, 1, $2943-2951$. [CrossRef]

2. Lü, L.; Lai, M.O. Mechanical Alloying; Springer: New York, NY, USA, 1998.

3. Wang, W.; Zhai, H.; Chen, L.; Zhou, Y.; Huang, Z.; Bei, G.; Greil, P. Sintering and properties of mechanical alloyed Ti3AlC2-Cu composites. Mater. Sci. Eng. A 2017, 685, 154-158. [CrossRef]

4. Shokrollahi, H. The magnetic and structural properties of the most important alloys of iron produced by mechanical alloying. Mater. Des. 2009, 30, 3374-3387. [CrossRef]

5. Polkin, I.S.; Borzov, A.B. New materials produced by mechanical alloying. Adv. Perform. Mater. 1995, 2, 99-109. [CrossRef]

6. Chaubey, A.K.; Scudino, S.; Mukhopadhyay, N.K.; Khoshkhoo, M.S.; Mishra, B.K.; Eckert, J. Effect of particle dispersion on the mechanical behavior of Al-based metal matrix composites reinforced with nanocrystalline Al-Ca intermetallics. J. Alloys Compd. 2012, 536, S134-S137. [CrossRef]

7. Caballero, E.S.; Cintas, J.; Cuevas, F.G.; Montes, J.M.; Herrera-García, M.; Oral, A.Y.; Bahşi, Z.B.; Özer, M.; Sezer, M.; Aköz, M.E. High temperature behavior of nanostructured Al powders obtained by mechanical alloying under NH3 flow. AIP Conf. Proc. 2015, 1653, 20025. [CrossRef]

8. Fogagnolo, J.; Velasco, F.; Robert, M.; Torralba, J. Effect of mechanical alloying on the morphology, microstructure and properties of aluminium matrix composite powders. Mater. Sci. Eng. A 2003, 342, 131-143. [CrossRef]

9. Kang, W.-K.; Yılmaz, F.; Kim, H.-S.; Koo, J.-M.; Hong, S.-J. Fabrication of Al-20 wt \%Si powder using scrap Si by ultra high-energy milling process. J. Alloys Compd. 2012, 536, S45-S49. [CrossRef]

10. Khan, A.S.; Farrokh, B.; Takacs, L. Effect of grain refinement on mechanical properties of ball-milled bulk aluminum. Mater. Sci. Eng. A 2008, 489, 77-84. [CrossRef]

11. Chen, C.; Lu, C.; Feng, X.; Shen, Y. Effects of annealing on Al-Si coating synthesised by mechanical alloying. Surf. Eng. 2017, 33, 548-558. [CrossRef]

12. Kainer, K.U. Metal Matrix Composites: Custom-Made Materials for Automotive and Aerospace; John Wiley \& Sons: Hoboken, NJ, USA, 2006.

13. Bose, A.; Eisen, W.B. Hot Consolidation of Powders and Particulates; Metal Powder Industries Federation: Princeton, NJ, USA, 2003.

14. Williamson, G.; Hall, W. X-ray line broadening from filed aluminium and wolfram. Acta Metall. 1953, 1, 22-31. [CrossRef]

15. Hryha, E.; Zubko, P.; Dudrová, E.; Pešek, L.; Bengtsson, S. An application of universal hardness test to metal powder particles. J. Mater. Proc. Technol. 2009, 209, 2377-2385. [CrossRef]

16. Abdoli, H.; Salahi, E.; Farnoush, H.; Pourazrang, K. Evolutions during synthesis of Al-AlN-nanostructured composite powder by mechanical alloying. J. Alloys Compd. 2008, 461, 166-172. [CrossRef]

17. Milligan, J.; Vintila, R.; Brochu, M. Nanocrystalline eutectic Al-Si alloy produced by cryomilling. Mater. Sci. Eng. A 2009, 508, 43-49. [CrossRef]

18. Miraghaei, S.; Abachi, P.; Madaah-Hosseini, H.R.; Bahrami, A. Characterization of mechanically alloyed $\mathrm{Fe}_{100-x} \mathrm{Si}_{x}$ and $\mathrm{Fe}_{83.5} \mathrm{Si}_{13.5} \mathrm{Nb}_{3}$ nanocrystalline powders. J. Mater. Process. Technol. 2008, 203, 554-560. [CrossRef] 
19. Safari, J.; Akbari, G.H.; Shahbazkhan, A.; Delshad Chermahini, M. Microstructural and mechanical properties of $\mathrm{Al}-\mathrm{Mg} / \mathrm{Al}_{2} \mathrm{O}_{3}$ nanocomposite prepared by mechanical alloying. J. Alloys Compd. 2011, 509, 9419-9424. [CrossRef]

20. Mhadhbi, M.; Khitouni, M.; Azabou, M.; Kolsi, A. Characterization of Al and Fe nanosized powders synthesized by high energy mechanical milling. Mater. Charact. 2008, 59, 944-950. [CrossRef]

21. Sivasankaran, S.; Sivaprasad, K.; Narayanasamy, R.; Satyanarayana, P.V. X-ray peak broadening analysis of Aa $6061_{100-x}-x$ wt \% $\mathrm{Al}_{2} \mathrm{O}_{3}$ nanocomposite prepared by mechanical alloying. Mater. Charact. 2011, 62, 661-672. [CrossRef]

22. Alizadeh, A.; Taheri-Nassaj, E. Mechanical properties and wear behavior of Al-2 wt \%Cu alloy composites reinforced by B4C nanoparticles and fabricated by mechanical milling and hot extrusion. Mater. Charact. 2012, 67, 119-128. [CrossRef]

23. Hall, E.O. The deformation and ageing of mild steel: III discussion of results. Proc. Phys. Soc. Sect. B 1951, 64, 747. [CrossRef]

24. Poirier, D.; Drew, R.A.; Trudeau, M.L.; Gauvin, R. Fabrication and properties of mechanically milled alumina/aluminum nanocomposites. Mater. Sci. Eng. A 2010, 527, 7605-7614. [CrossRef]

(C) 2017 by the authors. Licensee MDPI, Basel, Switzerland. This article is an open access article distributed under the terms and conditions of the Creative Commons Attribution (CC BY) license (http:/ / creativecommons.org/licenses/by/4.0/). 